\title{
DIAGNOSTIC AND THERAPEUTIC ROLE OF B SCAN ULTRASONOGRAPHY IN TRAUMATIZED EYES
}

\author{
Inderjit Kaur ${ }^{1}$, Prempal Kaur², Abhishek Handa ${ }^{3}$, Priya Agrawal ${ }^{4}$, Bhavkaran Singh ${ }^{5}$
}

\section{HOW TO CITE THIS ARTICLE:}

Inderjit Kaur, Prempal Kaur, Abhishek Handa, Priya Agrawal, Bhavkaran Singh. "Diagnostic and Therapeutic Role of B Scan Ultrasonography in Traumatized Eyes". Journal of Evolution of Medical and Dental Sciences 2014; Vol. 3, Issue 14, April 07; Page: 3543-3550, DOI: 10.14260/jemds/2014/2318

\begin{abstract}
AIM: To study the role of B scan ultrasonography as a diagnostic and therapeutic tool in the management of traumatized eyes. MATERIAL AND METHODS: In a prospective study done in the Regional Institute of Ophthalmology, Amritsar during 2011--2013, B scan ultrasonography was done on 50 traumatized eyes. RESULTS: In the present study, maximum incidence of ocular trauma (36\%) was in the age group of 15-29 years; more so in males (70\%) with the incidence of close globe injuries being $60 \%$. Patients mostly reported within 1 week of injury (70\%). Intraocular lesions diagnosed on B-scan imaging were cataract 25(50\%), dislocated lens 2(4\%), vitreous hemorrhage $20(40 \%)$, posterior vitreous detachment $5(10 \%)$, retinal detachment $13(26 \%)$ and foreign body in $2(4 \%)$ cases. More than one finding was observed in 27 cases. In 25 cases with cataract, vitreous hemorrhage was seen in $5(20 \%)$, posterior vitreous detachment in $4(16 \%)$ and retinal detachment in $4(16 \%)$. Of the 20 cases of vitreous hemorrhage $3(15 \%)$ had retinal detachment. B-Scan imaging proved beneficial in the management of the traumatized eyes.12(24\%) cases of traumatic cataract with no abnormality in the posterior segment underwent successful cataract extraction with IOL implantation. $27(54 \%)$ cases were referred to the vitreo-retinal surgeon while $11(22 \%)$ were followed up on appropriate medical treatment.
\end{abstract}

KEYWORDS: Regional institute of ophthalmology, Ultrasonography, Ocular trauma

INTRODUCTION: Ultrasound is an acoustic wave that consists of an oscillation of particles within a medium. Diagnostic ophthalmic ultrasonography (Amplitude modulated scanning) was first reported in 1956 by Mundt and Hughes. ${ }^{1}$ B scan was introduced in ophthalmic practice by Baum and Greenwood in 1958. ${ }^{2}$ For more than three decades, B-scan ultrasonography has played a key role as a valuable diagnostic imaging device in the field of Ophthalmology. The more invasive fluid-immersion technique of B -scan has now evolved to be less intrusive, utilizing the contact method which is most commonly used for the evaluation of the posterior segment of the eye in opaque media.

MATERIAL AND METHODS: A prospective diagnostic study was done to localize the various posterior segment lesions in patients of ocular trauma with opaque media from 2011 to 2013. All patients underwent detailed clinical examination which included recording of visual acuity, intraocular pressure measurement where possible, slit lamp biomicroscopy, indirect ophthalmoscopy and plain radiography of orbit when necessary. Patients with history of previous ocular surgery, known anterior or posterior segment pathology were excluded from the study. B scan ultrasonography over closed eye lids using a focused transducer was done with Paradigm P 60 gray scale real time ultrasound machine in sitting posture. A photograph using a polaroid camera was taken. Results were correlated with clinical findings and therapeutic management was planned accordingly. 
OBSERVATIONS AND RESULTS: Maximum incidence of ocular trauma (36\%) was in the age group of 15-29 years. The majority of the cases were male (70\%).

\begin{tabular}{|c|c|c|}
\hline Age group (in years) & No. of cases & Incidence (\%) \\
\hline $0-14$ & 03 & $6 \%$ \\
\hline $15-29$ & 18 & $36 \%$ \\
\hline $30-44$ & 13 & $26 \%$ \\
\hline $45-59$ & 09 & $18 \%$ \\
\hline 60 and $>60$ & 07 & $14 \%$ \\
\hline Total & 50 & $100 \%$ \\
\hline
\end{tabular}

The incidence of ocular trauma in males was $70 \%$ and that in females was $30 \%$

\begin{tabular}{|c|c|c|}
\hline \multicolumn{1}{|c|}{ SEX } & NUMBER OF CASES & INCIDENCE \\
\hline Male & 35 & $70 \%$ \\
\hline Female & 15 & $30 \%$ \\
\hline Total & $\mathbf{5 0}$ & $\mathbf{1 0 0 \%}$ \\
\hline
\end{tabular}

TABLE II: SHOWING SEX WISE DISTRIBUTION

The involvement of right eye was observed in $35(70 \%)$ cases and that of left eye in $15(30 \%)$ cases.

\begin{tabular}{|l|c|c|}
\hline \multicolumn{1}{|c|}{ LATERALITY } & NO. OF CASES & INCIDENCE (\%) \\
\hline Right eye & 35 & 70 \\
\hline Left eye & 15 & 30 \\
\hline
\end{tabular}

TABLE III: SHOWING THE LATERALITY OF OCULAR TRAUMA

The incidence of close globe injuries was $60 \%$ as compared to open globe injuries which was $40 \%$ of cases.

\begin{tabular}{|c|c|c|}
\hline TYPE OF INJURY & NO. OF CASES & PERCENTAGE \\
\hline CLOSED GLOBE & 30 & $60 \%$ \\
\hline OPEN GLOBE & 20 & $40 \%$ \\
\hline Total & $\mathbf{5 0}$ & $\mathbf{1 0 0 \%}$ \\
\hline
\end{tabular}

TABLE IV: SHOWING TYPE OF INJURY

\begin{tabular}{|c|c|c|c|}
\hline $\begin{array}{c}\text { TIME ELAPSED } \\
\text { SINCE INJURY }\end{array}$ & $\begin{array}{c}\text { TYPE OF } \\
\text { INJURY }\end{array}$ & $\begin{array}{c}\text { NO. OF } \\
\text { CASES }\end{array}$ & $\begin{array}{c}\text { TOTAL } \\
\text { Cases (\%) }\end{array}$ \\
\hline \multirow{2}{*}{ Within 1 week } & Open globe & $17(34 \%)$ & \multirow{2}{*}{$35(70 \%)$} \\
\cline { 2 - 3 } & Closed globe & $18(36 \%)$ & \\
\hline \multirow{2}{*}{ After 1 week } & Open globe & $3(6 \%)$ & \multirow{2}{*}{$15(30) \%$} \\
\cline { 2 - 3 } & Closed globe & $12(24 \%)$ & \\
\hline \multicolumn{2}{|c|}{50} & $\mathbf{1 0 0 \%}$ \\
\hline \multicolumn{2}{|c|}{ Total } & \multicolumn{3}{|c|}{ TABLE V: SHOWING TIME ELAPSED SINCE INJURY }
\end{tabular}

Most commonly the patient presented within 1 week of injury. 


\begin{tabular}{|l|c|c|}
\hline $\begin{array}{c}\text { INDICATIONS FOR ULTRASONIC } \\
\text { EYE EXAMINATION: }\end{array}$ & $\begin{array}{c}\text { NO. OF } \\
\text { CASES }\end{array}$ & PERCENTAGE \\
\hline Corneal opacity/edema & 10 & $20 \%$ \\
\hline Hyphaema & 05 & $10 \%$ \\
\hline Cataract & 25 & $50 \%$ \\
\hline Vitreous hemorrhage & 20 & $40 \%$ \\
\hline
\end{tabular}

\section{TABLE VI: SHOWING INDICATIONS FOR ULTRASONIC EYE EXAMINATION}

Out of 50 cases with opaque media $10(20 \%)$ cases had corneal opacity/edema, $5(10 \%)$ cases had hyphaema, 25(50\%) cases had cataract, and 20(40\%) cases had vitreous hemorrhage. More than one cause of opaque media was there in $10(20 \%)$ cases.

The various intraocular lesions diagnosed on B Scan imaging were cataract in 25(50\%) cases, dislocated lens in 2(4\%) cases, vitreous hemorrhage in $20(40 \%)$ cases, posterior vitreous detachment in $5(10 \%)$ cases, retinal detachment in $13(26 \%)$ cases, foreign body in $2(4 \%)$ cases. More than one finding was observed in 27 cases.

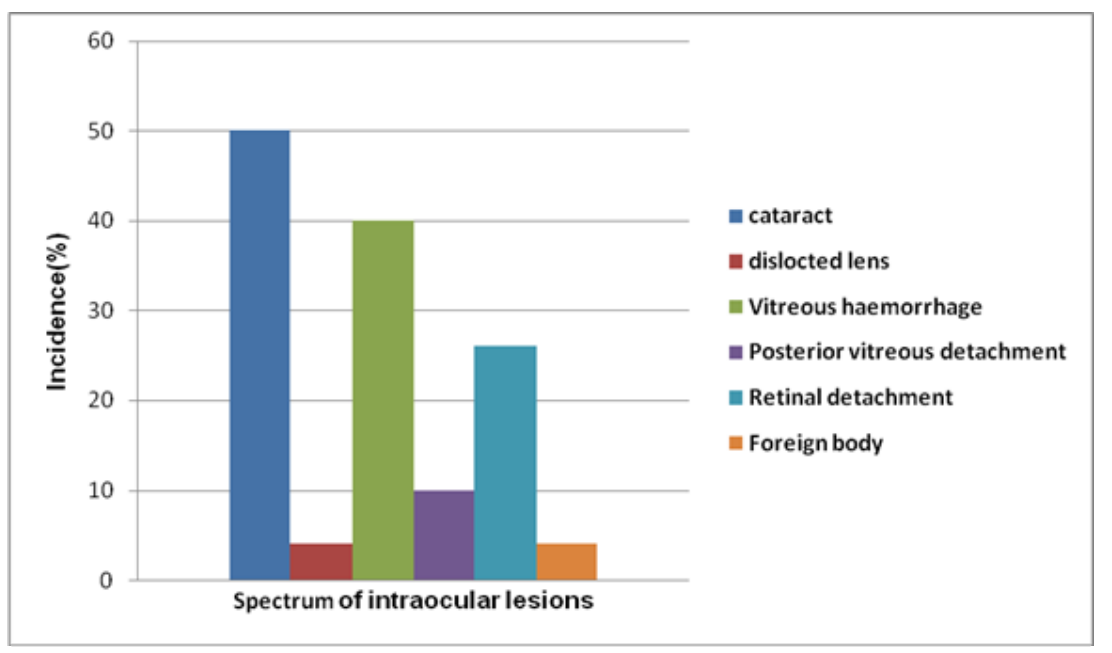

Fig. 1: DEPICTING THE SPECTRUM OF INTRAOCULAR LESIONS

\begin{tabular}{|c|c|c|}
\hline $\begin{array}{l}\text { ULTRASOUND } \\
\text { FINDINGS }\end{array}$ & $\begin{array}{l}\text { NO. OF } \\
\text { CASES }\end{array}$ & PERCENTAGE \\
\hline $\begin{array}{l}\text { Vitreous hemorrhage with } \\
\text { retinal detachment }\end{array}$ & 03 & $15 \%$ \\
\hline $\begin{array}{l}\text { Vitreous hemorrhage without } \\
\text { retinal detachment }\end{array}$ & 17 & $85 \%$ \\
\hline Total & 20 & $100 \%$ \\
\hline
\end{tabular}

Of the 20 cases of vitreous hemorrhage $3(15 \%)$ cases presented with retinal detachment and $17(85 \%)$ cases presented without retinal detachment. 
ORIGINAL ARTICLE

\begin{tabular}{|c|c|c|}
\hline $\begin{array}{l}\text { Ultrasonic evaluation of patients } \\
\text { with retinal detachment }\end{array}$ & $\begin{array}{c}\text { No. } \\
\text { of cases }\end{array}$ & Percentage \\
\hline Complete retinal detachment & 3 & $23.07 \%$ \\
\hline Partial retinal detachment & 10 & $76.92 \%$ \\
\hline Total & 13 & $100 \%$ \\
\hline
\end{tabular}

Of the 13 cases of retinal detachment $3(23.07 \%)$ cases were complete and $10(76.9 \%)$ cases were partial.

\begin{tabular}{|c|c|c|}
\hline $\begin{array}{c}\text { ULTRASONIC EVALUATION OF } \\
\text { PATIENTS WITH CATARACT }\end{array}$ & $\begin{array}{c}\text { No. } \\
\text { OF CASES }\end{array}$ & PERCENTAGE \\
\hline Vitreous hemorrhage & 5 & $20 \%$ \\
\hline Posterior vitreous detachment & 4 & $16 \%$ \\
\hline Retinal detachment & 4 & $16 \%$ \\
\hline $\begin{array}{l}\text { No abnormality detected in } \\
\text { the posterior segment }\end{array}$ & 12 & $48 \%$ \\
\hline Total & 25 & $100 \%$ \\
\hline
\end{tabular}

Out of the 25 cases of cataract, vitreous hemorrhage was seen in 5(20\%) cases, posterior vitreous detachment was seen in $4(16 \%)$ cases and retinal detachment was seen in $4(16 \%)$ cases and no abnormality was detected in posterior segment in $12(48 \%)$ cases.

\begin{tabular}{|c|c|c|}
\hline $\begin{array}{c}\text { ASSOCIATED ULTRASOUND } \\
\text { FINDINGS }\end{array}$ & $\begin{array}{c}\text { NO. } \\
\text { OF CASES }\end{array}$ & PERCENTAGE \\
\hline Vitreous hemorrhage & 1 & $50 \%$ \\
\hline Retinal detachment & 1 & $50 \%$ \\
\hline Total & 2 & $100 \%$ \\
\hline
\end{tabular}

Out of the 2 cases of foreign body revealed on ultrasonic evaluation of patients with ocular trauma, associated vitreous hemorrhage was found in $1(50 \%)$ case and retinal detachment was found in $1(50 \%)$ case. 


\section{ORIGINAL ARTICLE}

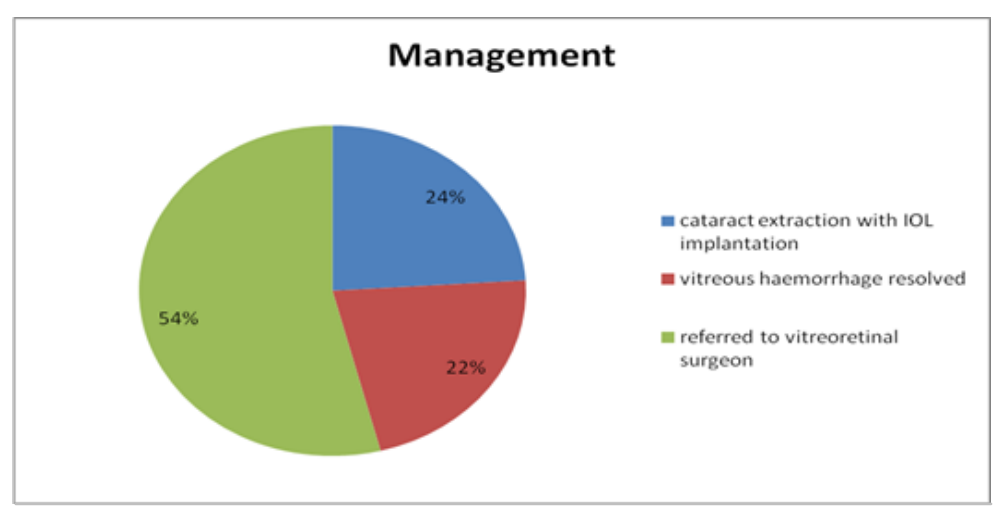

Fig. 2: showing management of various lesions in traumatized eye

$12(24 \%)$ cases of ocular trauma with cataract in which no abnormality in the posterior segment was detected on B Scan underwent cataract extraction with IOL implantation. 11(22\%) cases in which only vitreous hemorrhage was present, resolved spontaneously. Rest of the 27(54\%) cases were referred to vitreo-retinal surgeon.
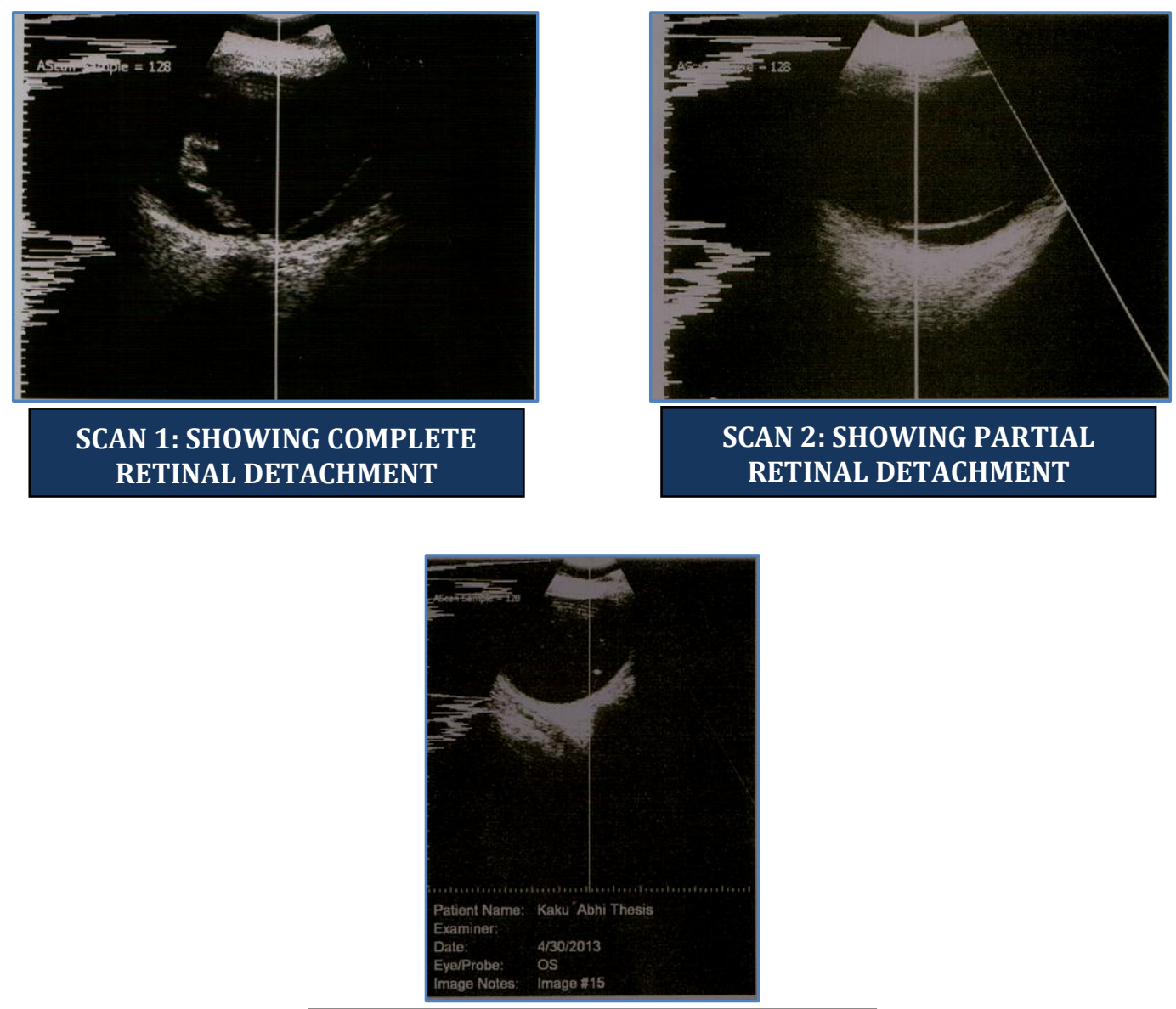

SCAN 3: SHOWING FOREIGN BODY

IN THE POSTERIOR SEGMENT 


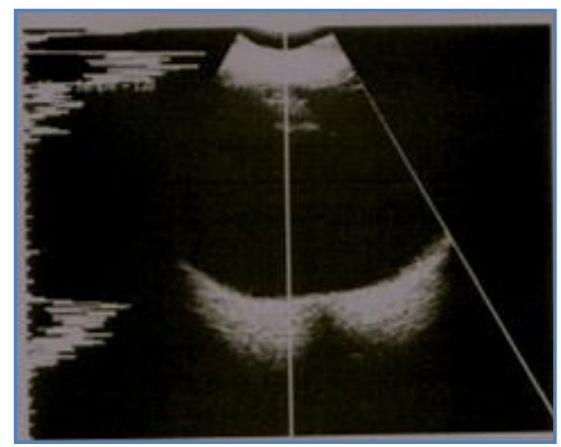

SCAN 4: SHOWING TRAUMATIC CATARACT

WITHOUT ANY ASSOCIATED ABNORMALITY IN THE POSTERIOR SEGMENT

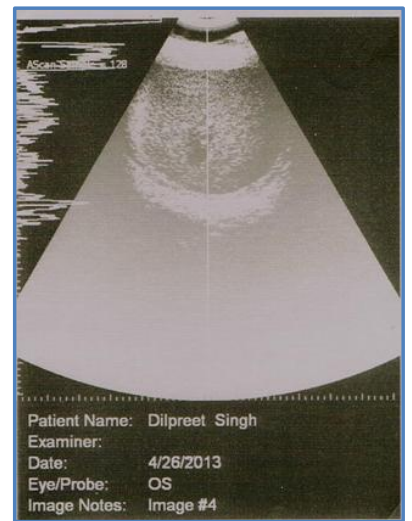

SCAN 5: SHOWING VITREOUS HEMORRHAGE

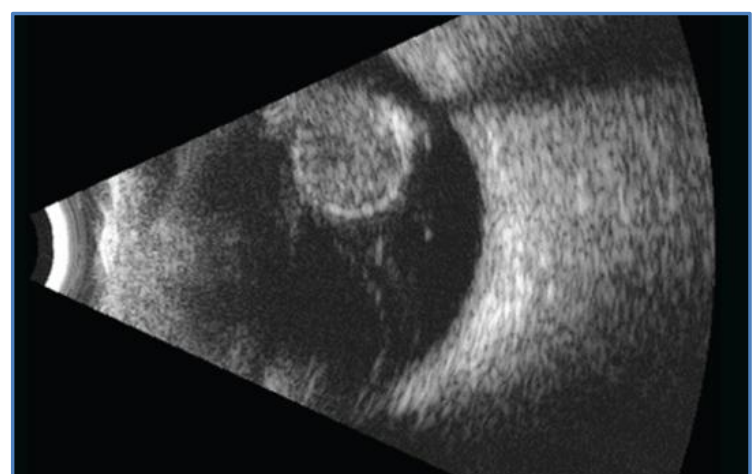

SCAN 6: SHOWING LENS DISLOCATED INTO THE VITREOUS HUMOR

DISCUSSION: Ocular trauma is one of the leading cause of blindness in our environment. ${ }^{3}$ The clinical use of ophthalmic ultrasound has increased dramatically over the past twenty years and has presently reached the point where it is universally regarded as an essential means of soft tissue examination of the eye and orbit. ${ }^{4}$ The sonography examination is rapid and cost-efficient, without the contraindications, such as pacemakers, that MRI has. Sonography avoids the irradiation associated with $\mathrm{CT}$ and the need for sedation in children. ${ }^{5}$ Presence of abnormal echoes in vitreous cavity is seen in vitreous hemorrhage.

Ultrasonography permits accurate localization of foreign body. In case of dislocated lens, Bscan USG could graphically demonstrate the posterior of lens \& associated abnormalities. Dislocation of lens into opaque media is a perfect indication for ultrasound. The abnormally placed lens is easily detected because of its shape and strong reflectivity. Ilsar et al in 1977 reported that out of 205 cases the highest incidence (32\%) of ocular injuries was found in the age group of 21-30 years. ${ }^{6}$ Gothwal et al in 1999 reported that in their study of ocular injuries, children $(<16$ years) constituted $46.8 \%$ of the total affected population. ${ }^{7}$ Gupta et al in 1990 reported the incidence of ocular trauma in males to be $84 \%$ and in females to be $16 \% .{ }^{8}$ Wilson et al in 1991 found the incidence of ocular trauma in males to be $78 \%$ and in females to be $22 \% .{ }^{9}$ Serrano et al in 2003 reported the incidence in males to be $64.9 \%$ and in females to be $35.1 \% .^{10}$

Smith et al in 2006 reported the incidence of closed globe and open globe to be $68.5 \%$ and $31.4 \%$ respectively. ${ }^{11}$ The closed globe injuries are more common than open globe injuries probably because the agents causing these types of injuries are more common in nature while those causing open globe injuries are generally sharp and pointed objects only. Babar etal in 2007 reported that 40 
$\%$ of patients presented within 1 week of injury and $60 \%$ presented after one week. ${ }^{12}$ In their retrospective study of 96 patients of ocular trauma Gyasi et al in 2004 reported that one third of the cases reported in less than $24 \mathrm{hrs}$. after injury. 57.3\% reported between 24 and $48 \mathrm{hrs}$. and 21\% reported after 1 week of injury. 13

Gadkari et al conducted a study using a simultaneous A and B scan in 100 patients. According to them information about state of posterior segment can be sought in presence of opaque media and this helps in planning of surgery. A scan vector guided by B scan displays an important role in differentiating retinal detachment from vitreous membranes, band and posterior vitreous detachment. ${ }^{14}$

Zakov reported that in 50 eyes with opaque media, retinal detachment was diagnosed with $90 \%$ accuracy by a prospective study. ${ }^{15}$ Munk et al in 1991 demonstrated lens fragmentation with individual fragments distinctly discernible on ultrasound. ${ }^{16}$ Conventional ultrasonography is more useful for localizing foreign bodies in relation to the sclera. It is also superior in demonstrating ocular damage associated with intraocular foreign bodies. ${ }^{17}$

Haile utilized B-scan ultrasonography on 318 eyes of 298 patients for evaluation of 285 eyes with opaque media, 3 eyes with clear media but with suspected intra ocular abnormalities and for proptosis in 30 cases. 209(66\%) eyes had one or more detectable abnormality. Most common abnormality was retinal detachment (39\%), followed by vitreous opacities (31\%), eye ball size abnormalities (12\%), intraocular foreign body (4\%), posterior staphyloma (3\%) and retinal detachment with vitreous opacities (2\%).18

The above studies correlate well with the findings in our study. However Saxena in 2002 reported the incidence of closed globe and open globe to be $42.2 \%$ and $53.9 \%$ respectively. ${ }^{19}$

CONCLUSION: B Scan proved to be a valuable tool in diagnosing the posterior segment lesions in traumatized eyes with opaque media. The results were encouraging and made a significant difference in the management outcome. Patients with cataract without any posterior segment findings were operated with intraocular lens implantation and the rest were referred to the vitreo-retinal surgeon for management.

\section{REFERENCES:}

1. Mundt GH, Hughes WF. Ultrasonics in ocular diagnosis. Am J Opthalmol. 1956; 41:488-98.

2. Baum G, Greenwood I. The application of ultrasonic locating techniques in ophthalmology. A.M.A Archives of ophthalmology 1958; 60:263-79.

3. Akinsola FB. Eye injuries in children: Guinness Eye Centre, Lagos University Teaching Hospital experience. Nig J Surg 1996; 3:12-6.

4. Colemon DJ, Lizzi FL, Jack RL. Ultrasonography of the eye and orbit. Philadelphia, Lea and Febiger, 1977, P.VII. Coleman et al. Ultrasonography, 1977:3.

5. Ramji FG, Slovis TL, Baker JD. Orbital sonography in children. Pediatr Radiol 1996; 26:245-258.

6. Ilsar M, Chirambo M, Belkin M. Ocular injuries in Malawi. Br J Opthalmol 1982 Feb.; 66(2):1458.

7. Gothwal VK, Adolph S, Jalali S, Naduvilath TT. Demography and prognostic factors of ocular injuries in south India. Aust NZJ Opthalmol 1999; 27(5):318-35.

8. Dasgupta S, Mukherjee R, Ladi D S, Gandhi V H, Ladi B S. Pediatric ocular trauma--a clinical presentation. J Postgrad Med 1990; 36:20. 
9. Wilson MR, Wooten F, Williams J. Frequency and characteristics of ocular trauma in an urban population. J Natl Med Assoc. 1991 August; 83(8):697-702.

10. Serrano JC, Patricia C, Juan DA. Epidemiology of childhood ocular trauma in a north eastern Colombian region. Arch Opthalmol 2003; 121:1439-45.

11. Smith AR, O'Hagan SB, Gole GA. Epidemiology of open- and closed-globe trauma presenting to Cairns Base Hospital, Queensland. Clin Experiment Ophthalmol. 2006 Apr; 34(3):252-9.

12. Babar TF, Khan MT, Marwat MZ, Shah SA, Murad Y, Khan MD. Patterns of ocular trauma. J Coll Physicians Surg Pak. 2007 Mar; 17(3):148-53.

13. Gyasi M, Amoaku W, Adjuik M. Epidemiology of hospitalized ocular injuries in the upper East region of Ghana. Ghana Med J. 2007 Dec; 41(4):171-5.

14. Gadkari SS, Sriniwas NK. Simultaneous A And B Scan In Diagnostic Ocular Ultrasonography. Indian Journal of Ophthalmology 1992; 40:35-7.

15. Zakov ZN. Ultrasonographic Mapping of Vitreoretinal Abnormalities. Am J Opthalmol 1983 Nov; 96(5):622-31.

16. Munk PL, Vellet AD, Levin M, Lin DT, Collyer RT. Sonography of the eye. AJR 1991; 157:1079-86.

17. Deramo, Shah G, Baumal CR, Fineman MS, Correa ZM, Benson WE, Rapuano CJ et al. The Role of Ultrasound Biomicroscopy in Ocular Trauma. Trans American Opthalmological Society 1998; 96:355-67.

18. Haile M. B Scan Ultrasonography in Ophthalmic Diseases. East Africa Medical Journal 1996; 73(11):703-7.

19. Saxena R. Pattern of pediatric ocular trauma in India. Indian J Pediatr 2002; 69(1): 863-7.

\section{AUTHORS:}

1. Inderjit Kaur

2. Prempal Kaur

3. Abhishek Handa

4. Priya Agrawal

5. Bhavkaran Singh

\section{PARTICULARS OF CONTRIBUTORS:}

1. Associate Professor, Department of Ophthalmology, Regional Institute of Ophthalmology, Amritsar.

2. Associate Professor, Department of Ophthalmology, Regional Institute of Ophthalmology, Amritsar.

3. Post Graduate, Department of Ophthalmology, Regional Institute of Ophthalmology, Amritsar.
4. Post Graduate, Department of Ophthalmology, Regional Institute of Ophthalmology, Amritsar.

5. Under Graduate, Department of Ophthalmology, Regional Institute of Ophthalmology, Amritsar.

\section{NAME ADDRESS EMAIL ID OF THE} CORRESPONDING AUTHOR:

Dr. Inderjit Kaur, No. 20, Doctor's Avenue, Majitha Road, Amritsar.

E-mail:renudoc@yahoo.com

Date of Submission: 29/01/2014. Date of Peer Review: 30/01/2014. Date of Acceptance: 11/02/2014. Date of Publishing: 01/04/2014. 